Vol. I No. 01Hal. 37 - 42

15 - Januari 2018

\title{
Komunitas Makrozoobentos di Aek Hisa, Aek Doras, dan Aek Sigeon Kecamatan Lintong Ni Huta Tapanuli Utara
}

\author{
Yusri Fefiani
}

\author{
Dosen PNS DPK FKIP UISU
}

\begin{abstract}
ABSTRAK
Penelitian Tentang Komunitas Makrozzobentos pada Aek Hisa, Aek Doras, dan Aek Sigeon di Kecamatan Lintong Ni Huta Tapanuli Utara telah dilakukan dari bulan Oktober sampai dengan November 1994. Makrozoobentos yang didapatkan pada Aek Hisa terdiri dari 701 individu dari 18 Fmili dari 8 Ordo. Pada Aek Doras ditemukan 652 individu dari 15 famili dari 5 Ordo dan pada Aek Sigeon ditemukan 736 individu dari 24 Famili dari 11 ordo, Kepadatan dan Kepadatan Relatif hewan bentos yang tertinggi dari ketiga strata itu adalah Diptera kemudian diikutiTrichoptera. Komposisi Genus Makrozoobentos Aek Hisa dengan Aek Doras, Aek Hisa dengan Aek Sigeon tidak berbeda nyata, tetapi antara Aek Doras dengan Aek Sigeon berbeda nyata pada $\mathrm{P}=0,01$. Indeks diversitas makrozoobentos pada ketiga strata tidak berbeda nyata.
\end{abstract}

\section{PENDAHULUAN}

\section{LatarBelakang}

Hewan benthos adalah organisme yang hidup di permukaan atau dalam dasar perairan. Ada yang hidup menggali lubang, di bawah-bawah batu atau kerikil, membenamkan diri dalam lumpur atau pasir, serta pada detritus di dasar perairan. Hewan benthos banyak jenisnya, ada yang tergolong moluska, insekta, krustase dan annelida. Dari sekian banyak jenis hewan benthos, larva dan nimfa insekta yang terbanyak didapatkan dalam perairan (Odum, 1971, Goldman dan Horne, 1983). Kehidupan hewan benthos sangat tergantung pada keadaan lingkungannya. Hewan benthos yang hidup pada lingkungan perairan mengalir (lotik) akan berbeda komposisi dan jenisnya dengan perairan tenang (lentik). Hewan benthos yang hisup di dasar berlumpur berbeda dengan yang hidup di dasar berbatu-batu. Pada perairan dengan dasar berbatu-batu biasanya didaptkan hewan benthos dari golongan Trichoptera dan Ephemeroptera yang memiliki kemampuan adaptasi yang baik pada lingkungan tersebut (Hynes, 1972 dan Pennak, 1978). Hewan benthos kehadirannya tidak saja ditentukan oleh toleransinya terhadap faktor fisika-kimia (abiotik), tetapi juga oleh faktor biotik seperti sumber makanan dan produsen pada dasar perairan (Moss, 1980, Anwar, Damanik. Hisyam dan Whitten, 1984). Faktor fisika-kimia yang berpengaruh terhadap kehadiran hewan benthos adalah kecepatan arus, substrat, suhu air oksigen terlarut, zat hara terlarut dan pH (Hynes, 1972, Hawkes, 1979, Goldman dan Horne, 1983). Selain itu kekeruhan dan warna air juga berpengaruh secara tidak langsung terhadap kehadiran hewan benthos (Hawkes, 1979). Komposisi dan struktur komunitas hewan benthos pada suatu perairan bias berbeda dengan perairan lainnya bila faktor fisika-kimia airnya berbeda. Rondo (1982) mengemukakan bahwa komposisi dan struktur komunitas hewan benthos di sungai Cikapundung Bandung berbeda faktor fisika-kimia airnya antara lain BOD dan limbah industry. Demikian pula dengan sinaga et al. (1994) mengemukakan bahwa perubahan keragaman makro 200 benthos dipengaruhi oleh faktor fisika-kimia air serta kondisi perairan tempat hidupnya. Komposisi dan struktur komunitas hewan benthos antara Aek Doras dan Aek Hisa yang bermuara ke Aek Sigeon mengkin berbeda pula karena faktor fisika-kimia dan sumber mata airnya berbeda. Syafei dan Hamzah (1993) melaporkan bahwa faktor fisika-kimia air Aek Hisa sangat berbeda dengan Aek Doras dan Aek Sigeon. Sampai saat ini penelitian untuk membandingkan komposisi hewan benthos 
Yusri Fefiani : Komunitas Makrozoobentos di Aek Hisa, Aek Doras, dan Aek Sigeon Kecamatan Lintong Ni Huta Tapanuli Utara.

antara sungai yang sumbernya berupa air panas dengan yang biasa di Indonesia belum ada. Penelitian yang pernah dilakukan adalah penelitian tentang hewan benthos sebagai indikator ekologi di Sungai Cikapundung Bandung oleh Rondo (1982) yang membandingkan komposisi dan struktur komunitas daerah hulu yang belum tercemar. Penelitian lainnya tentang komposisi hewan benthos di sungai Batang Arau Kotamadya Padang oleh Warni (1988) yang membandingkan daerah hulu yang belum tercemar dengan muara yang tercemar. Jadi terasa sekali bahwa pengetahuan tentang perbandingan komposisi dan struturkomunitas hewan benthosantara beberapa biotop di Indonesia masih kurang sekali. Untuk menganalisis komposisi dan struktur komunitas hewan di suatu biotop ada beberapa cara. Biasanya orang menggunakan perbandingan kepadatan populasi, indeks diversitas, indeks equitabilitas dan indeks similaritas dalam analisis tersebut (Poole, 1974). Untuk mengambil sampel populasi hewan benthos pada suatu daerah ada beberapa metode tang sering digunakan. Metoda-metoda yang sering digunakan antara lain dengan menggunakan Ekman Dredge, Shovel Sampler, Scoop Sampler dan Surber Sampler. Dari sekian metoda yang ada tak satupun diantaranya yang dapat digunakan utnuk semua keompok hewan benthos. Tiap-tiap metoda hanya memberikan hasil yang sahih untuk kelompok hewan benthos tertentu. Metoda Surber Sampler adalah metoda yang terbaik dan sering digunakan untuk mengkoleksi hewan benthos pada perairan mengalir yang tidak begitu dalam (Hyne, 1972, Michael, 1984)

\section{Perumusan Masalah}

Berdasarkan pembatasan masalah tersebut maka rumusan masalah dalam penelitian ini adalah : bagaimana bentuk Komunitas Makrozoobentos di Aek Hisa, Aek Doras, dan Aek Sigeon Kecamatan Lintong Ni HutaTapanuli Utara yang diperkirakan bahwa komunitas di ketiga lokasi tersebut berbeda.

\section{Tujuan Penelitian}

Adapun yang menjadi tujuan dari penelitian ini adalah :

1. Untuk mengetahui Bentuk Komunitas Makrozoobentos di Aek Hisa Kecamatan Lintong Ni Huta Tapanuli Utara

2. Untuk mengetahui Bentuk Komunitas Makrozoobentos di Aek Doras Kecamatan Lintong Ni Huta Tapanuli Utara

3. Untuk mengetahui Bentuk Komunitas Makrozoobentos di Aek Sigeon Kecamatan Lintong Ni Huta Tapanuli Utara

\section{Manfaat Penelitian}

Manfaat yang diharapkan sehubungan dengan penelitian ini antara lain :

Sebagai referensi penelitian bagi peneliti selanjutnya yang ingin melakukan penelitian di bidang yang sama atau di topic penelitian yang sama ataupun berbeda.

\section{METODE PENELITIAN}

Waktu dan Tempat Penelitian Penelitian ini dilakukan dari Bulan Oktober sampai dengan November 1994. Sampel diambil dari Aek Hisa, Aek Doras dan Aek Sigeon di kecamatan Lintong Nihuta Tapanuli Utara. Sampel tersebut kemudian diidentifikasi dan dihitung jumlahnya. Metoda Penelitian Dilakukan secara stratified sistematik sampling. Lokasi pengambilan sampel dilakukan pada tiga strata yaitu :

Strata I : Pada Aek Hisa yang mengandung air panas Strata II : Pada Aek Doras Strata III : Pada Aek Sigeon. Pada msing-masing strata diambil empat stasiun. Untuk strata I dan II, stasiunnya mulai $100 \mathrm{~m}$ ke arah hulu dari pertemuan kedua strata. Sedangkan strata II 
Yusri Fefiani : Komunitas Makrozoobentos di Aek Hisa, Aek Doras, dan Aek Sigeon Kecamatan Lintong Ni Huta Tapanuli Utara.

kearah hilir. Peletakkan stasiun pada masing-masing strata dilakukan secara sistematik random sampling yang jaraknya $100 \mathrm{~m}$ antar stasiun. Pada tiap-tiap stasiun diambil 5 sampel dengan surbernet. Bahan dan Alat-alat : Bahan yang digunakan adalah kertas special indicator universal $\mathrm{pH}$ 6.5-10, formalin 4\%, alkohol 70\%, amilum 1\%, MnSO4, $4 \mathrm{H} 2 \mathrm{O}, \mathrm{KOHVIKI} 25 \%, \mathrm{H} 2 \mathrm{SO} 4$ pekat, natrium thio sulfat (Na2S2O3), 0,025 N.

Alat-alat yang digunakan adalah : surber net $(30 \times 30 \mathrm{~cm})$, baki plastic, pinset, cawan peri, kaca arloji, mikroskop binokuler, termometer $\mathrm{Hg}$, meteran buret+standar, gelas ukur $50 \mathrm{ml}$, erlenmeyer $100 \mathrm{ml}$, botol Winkler, pipet, gabus, stopwatch. 3.4. Cara Kerja DI lapangan Pengukuran Beberapa Faktor Fisika-Kimia. Pada stasiun yang telah ditentukan diukur suhu udara kemudian air dengan termometer, $\mathrm{pH}$ dengan kertas special indicator universal, dan kecepatan arus dengan gabus. Suhu dan $\mathrm{pH}$ air diukur pada kedalaman 0,25 m. 3.4.1.2. Pengambilan Sampel Air Untuk menghitung kadar O2 dan BOD pada tiap-tiap stasiun diambil air dengan botol Winkler. Pengukuran DO awal pada botolterang langsung dilakukan dilapangan. Pada waktu yang sama diambil juga sampel air dengan botol gelap untu analisis BOD. Analisis fisika-kimia air berupa kandungan unsur-unsur mineral dilakukan di Laboratorium Sucofindo Medan. Pengambilan Sampel Hewan Benthos Sampel hewan benthos diambil pada kedalaman $0,25 \mathrm{~m}$ pada tiap-tiap stasiun sebanyak 5 sampel secara acak dengan menggunakan surber met (mesh 30 mikron). Surbernet dibenamkan pada dasar perairan dengan posisi mulutnya menetang arus. Kuadratnya ditahan dengan kaki atau batu. Bagian dalam kerangka kuadrat diadukaduk sehingga hewan benthos yang dihanyutkan arus terjaring dalam net. Batu-batu yang berada dalam kerangka kuadrat diambil kemudian disikat dengan kuat dan ditampung dengan baki plastic. Hewan benthos yang terjaring dalam surber net, dimasukkan ke baki plastic kemudian dibilas dengan air. Setelah itu dipindahkan ke botol sampel dan diawetkan dalam formalin $4 \%$ serta diberi label. Selanjutnya sampel dibawa untuk diidentifikasi dan dihitung jumlahnya. Di Laboratorium Sampel yang didapatkan dari lapangan disortir di laboratorium. Kemudian diamati di bawah mikroskop binokuler untuk diidentifikasi dan dihitung jumlahnya. Setelah itu sampel tersebut diawetkan dalam alkohol $70 \%$. Pengukuran BOD dilakukan seperti cara penentuan DO/ hari dan dicatat hasil rata-rata titrasinya. Kadar BOD dihitung dengan rumus: BOD 5 = DO 0 hari - DIO 5 hari Penentuan kadar oksigen dihitung dengan rumus: Ppm O2 = ml titranx N titran x 8 x $1000 \mathrm{ml}$ sampel (volume botol-2) volume botol

Analisis Data Hewan benthos yang didapat, setelah diidentifikasi dan dihitung jumlahnya, dianalisis komposisi dan struktur komunitasnya. Pada Aek Hisa didapatkan 35,10 ekor 900 $\mathrm{cm}$ Aek Doras 32,60 ekor $900 \mathrm{~cm}$ dan pada Aek Sigeon 36,75 ekor/900 cm. Pada Aek Hisa, kepadatan populasi hewan benthos yang tertinggi adalah ordo Diptera (23.60 ekor / $90 \mathrm{~cm})$, kemudian diikuti oleh ordo Trichoptera $(6,10$ ekor $/ 900 \mathrm{~cm}$ "), sedangkan yang terendah adalah ordo Mesogastropoda $(0.55$ ekor $/ 900 \mathrm{~cm})$, kemudian diikuti ordo Isopoda (0.10 ekor / $900 \mathrm{~cm}$ "). Famili yang tertinggi kepadatan populasinya adalah Chironomidae (18,60 ekor / $900 \mathrm{cmo})$, kemudian diikuti oleh Tipulidae $(5$ ekor / $900 \mathrm{~cm})$, sedangkan yang terendah adalah family dari ordo Isopoda. (0,10 ekor/900 cm). Pada Aek Doras, kepadatan populasi hewan benthos yang tertinggi adalah ordo Diptera $(24,85$ ekor $900 \mathrm{~cm})$, kemudian diikuti oleh ordo Trichoptera (440 ekor / $900 \mathrm{~cm}$ "), sedangkan yang terendah adalah ordo Lepidoptera (0,50 ekor / $900 \mathrm{~cm}$ "). Famili yang kepadatan populasinya tertinggi adalah Chironomidae $(16,10$ ekor/900 cm), kemudian diikuti oleh Tipulidae $(8.75$ ekor $900 \mathrm{~cm}$ ), sedangkan yang terendah adalah family Siphlonuridae (0,50 ekor / 900 $\mathrm{cm}$ ?). Pada Aek Sigeon, kepadatan populasi hewan benthos yang tertinggi adalah ordo 
Yusri Fefiani : Komunitas Makrozoobentos di Aek Hisa, Aek Doras, dan Aek Sigeon Kecamatan Lintong Ni Huta Tapanuli Utara.

Diptera $(1930$ ekor/900 cm), kemudian diikuti oleh ordo Trichoptera $(8.30$ ekor $900 \mathrm{~cm})$, sedangkan yang terendah adalah ordo Neuroptera, Digenea serta Amphipoda (0, 10 ekor / $900 \mathrm{~cm}$ "). Famili yang kepadatan populasinya tertinggi adalah Chironomidae (13, 10 ekor / $900 \mathrm{cmo})$, kemudian diikui oleh Tipulidae $(6.00$ ekor / $900 \mathrm{~cm})$, sedangkan yang terendah adalah Tabanidae, Simulidae, Sysyridae, Platyhelminthidae dan famili dari ordo Amphipoda (0, 10 ekor / 900 cm'). Berbedanya kepadatan ordo dan famili pada Aek Hisa, Aek Doras, dan Aek Sigeon disebabkan oleh faktor-faktor yang mempengaruhi penyebaran dan kepadatan populasi hewan benthos tersebut tidak sama. Selain itu, penyebaran dan kepadatan populasi hewan benthos yang menghuni habitat perairan mengalir dengan dasar substrat berbatu-batu dipengaruhi oleh beberapa faktor antara lain kecepatan arus, oksigen terlarut, dan zathara terlarut (Roeder, 1953, Pennak, 1978, Hawkes, 1979). Kepadatan populasi ordo Diptera terutama famili Chironomidae dan Tipulidae tinggi pada setiap strata. Kepadatan tertinggi didapatkan pada Aek Hisa untuk Chironomidae dan Aek Doras untuk Tipulidae. Tingginya kepadatan populasi Chironomidae pada Aek Hisa menandakan habitat ini disenangi oleh Chironomidae, sedangkan Aek Dorasoleh Tipulidae. Menurut lamberti dan Vincent (1985), family Chironimidae masih terdapat pada perairan yang suhunya telah mencapai 42 "C karena hewan ini mempunyai kemampuan adaptasi yang baik terdapat suhu lingkungan perairan yang tinggi. Larva insekta dari bangsa Diptera tersebar meluas pada berbagai habitat perairan, baik mengalir, tenang, bahkan perairan dengan suhu yang tinggi menurut ukuran toleransi organisme air sekalipun masih ditemukan larva Diptera terutama famili Chironomidae (Brown. 1971; Pennak, 1978; Moss, 1980). Kepadatan populasi ordo Trichoptera terutama famili Hydropsychydae tinggi pada Aek Sigeon.

Hal ini dimungkinkan karena Aek Sigeon berarus deras serta mengandung bahan organik yang tinggi dibandingkan strata lainnya. Tingginya bahan organi pada Aek Sigeon disebabkan aktifitas penduduk serta masukan dari persawahan sekitarnya. Kelompok Hydropsychydae dalam hal mencari makanannya tergantung pada arus yang membawa partikel-partikel yang terlarut, serta membuat sarang dengan struktur jaring-jaring dari kelenjar ludah sehingga dapat menjaring partikel yang terbawa arus (Hynes, 1972). Selanjutnya Hawkes (1979) menambahkan bahwa struktur jaring-jaring ini terbesar diantara bangsa Trichoptera lainnya dan paling banyak ditemukan pada semua bagian sungai. Sedikitnya ditemukan ordo Mesogastropoda dan Digenea disebabkan tipe dasar perairan yang terdiri dari batu-batu besar atau kerikil kurang cocok bagi kelompok ini. Kelompok hewan benthos ini umumnya menghuni habitat perairan yang tergenang atau mengalir sangat lambat dengan dasar perairan lumpur. Keadaan seperti ini tidak ditemukan pada ketiga strata daerah penelitian tersebut. Kelompok Mollusca dan Annelida adalah penghuni dasar perairan tenang, berlumpur serta kaya bahan organik. Sedangkan rendahnya ordo Lepidoptera dan Neuroptera disebabkan oleh faktor-faktor yang mendukung kehidupannya kurang terpenuhi (Hawkes, 1979; Tudorance, 1979). Selanjutnya kelompok lepidoptera menyukai habitat perairan dengan kadar oksigen tinggi serta memakan tumbuh-tumbuhan air. Sedangkan Neuroptera kurang menyukai arus deras serta kadar garam tinggi (Roeder, 1953). Kepadatan relatif hewan benthos pada ketigastrata tidak begitu berbeda. Pada Aek Hisa didapatkan 99.97\%, Aek Doras 99,93\% dan Aek Sigeon 99,18\%. Pada Aek Hisa kepadatan relatif hewan benthos yang tinggi ordo Diptera $(67,19 \%)$, kemudian diikuti ordo Trichoptera $(17.40 \%)$ 
Yusri Fefiani : Komunitas Makrozoobentos di Aek Hisa, Aek Doras, dan Aek Sigeon Kecamatan Lintong Ni Huta Tapanuli Utara.

\section{KESIMPULAN DAN SARAN}

1. Kesimpulan

Pada Aek Hisa didapatkan 35,10 ekor $900 \mathrm{~cm}$ Aek Doras 32,60 ekor $900 \mathrm{~cm}$ dan pada Aek Sigeon 36,75 ekor/900 cm. Pada Aek Hisa, kepadatan populasi hewan benthos yang tertinggi adalah ordo Diptera $(23.60$ ekor / $90 \mathrm{~cm})$, kemudian diikuti oleh ordo Trichoptera (6,10 ekor / $900 \mathrm{~cm}$ "), sedangkan yang terendah adalah ordo Mesogastropoda (0.55 ekor/900 cm), kemudian diikuti ordo Isopoda (0.10 ekor / $900 \mathrm{~cm}$ "). Famili yang tertinggi kepadatan populasinya adalah Chironomidae $(18,60$ ekor / $900 \mathrm{cmo})$, kemudian diikuti oleh Tipulidae (5 ekor / $900 \mathrm{~cm}$ ), sedangkan yang terendah adalah family dari ordo Isopoda. (0,10 ekor/900 cm). Pada Aek Doras, kepadatan populasi hewan benthos yang tertinggi adalah ordo Diptera $(24,85$ ekor $900 \mathrm{~cm})$, kemudian diikuti oleh ordo Trichoptera (440 ekor / $900 \mathrm{~cm}$ "), sedangkan yang terendah adalah ordo Lepidoptera (0,50 ekor / 900 cm"). Famili yang kepadatan populasinya tertinggi adalah Chironomidae (16,10 ekor/900 $\mathrm{cm})$, kemudian diikuti oleh Tipulidae $(8.75$ ekor $900 \mathrm{~cm})$, sedangkan yang terendah adalah family Siphlonuridae (0,50 ekor / $900 \mathrm{~cm}$ ?). Pada Aek Sigeon, kepadatan populasi hewan benthos yang tertinggi adalah ordo Diptera $(1930$ ekor/900 cm), kemudian diikuti oleh ordo Trichoptera $(8.30$ ekor $900 \mathrm{~cm})$, sedangkan yang terendah adalah ordo Neuroptera, Digenea serta Amphipoda (0, 10 ekor / $900 \mathrm{~cm}$ "). Famili yang kepadatan populasinya tertinggi adalah Chironomidae (13, 10 ekor / $900 \mathrm{cmo})$, kemudian diikui oleh Tipulidae (6.00 ekor $/ 900 \mathrm{~cm})$, sedangkan yang terendah adalah Tabanidae, Simulidae, Sysyridae, Platyhelminthidae dan famili dari ordo Amphipoda (0, 10 ekor / 900 cm').

\section{Saran}

1. Perlu adanya penelitian lebih lanjut mengenai penelitian Makrozoobentos

2. Perlu adanya kunci determinasi yang jelas mengenai kelimpahan Makrozoobentos yang ada di tempat penelitian sehingga menjadi referensi kunci yang jelas.

\section{DAFTAR PUSTAKA}

Anwar, J., S.J. Damanik, N. Hisyam, A.J. Whitten. 1984. Ekologi Ekosistem Sumatera. Gadjah Mada University Press. Yogyakarta.

Brown, A.L. 1971. Ecology of Freshwater. Heineman Educational Books. London.

Goldman, R.G., A.J., Horne. 1983. Lymnology International Student Edit. Mc.GrawhillBooks Company.

Hawkes, H.A.1979. Invertebrates as indocator of River Water Quality. In: A Jaws and L. Evison (Ed) Biological Indicator of Water Quality. John Willey and Sons. New York.

Hynes, H.B.N. 1972. The Ecology of Running Water. Liverpool University Press. London.

Michael, E.T.. 1984. Ecological Methods For Field and Laboratory Inverstigation. Tata McGraw Hill. Publisihing Company. Ltd. New Delhi.

Moss, B. 1980. Ecology of Freshwater. Blackwell Scientific Publications. Oxford. London.

Odum, E.P. 1971. Fundamens of Ecology. W.B. Saunder Co. Toppan Co Ltd. 
Yusri Fefiani : Komunitas Makrozoobentos di Aek Hisa, Aek Doras, dan Aek Sigeon Kecamatan Lintong Ni Huta Tapanuli Utara.

Pennale, R.W. 1978. Freshwater Invertebrates of The United States. Second Edition. John Willey and sons. New York.

Poole, R.W. 1974. An Introduction to Quantitive Ecology. Mc.Grawhill Book Company. New York.

Roeder, K.D.1953. Insect Physiology. John Willey and Sons. New York.

Rondo, M. 1982. Hewan Benthos sebagai Indikator Ekologi di Sungai Cikapundung Bandung. ITB. Tesis PascaSarjana.

Sinaga, T, M.F. Raharjo, D.S.Sjafei. 1994. Komunitas Makrozoobentos di Sungai Banjaran. Kabupaten Banyumas, Jawa Tengah. IPB Bogor.

Warni, T.1988. Komposisi HEwan Benthos di Sungai batang Arau Kodya Padang. Universitas Andalas. Tesis Sarjana Biologi. 